\title{
Soy and Breast Cancer, have we Analyzed all the Risks?
}

Koo J and Schramm L*

Department of Biological Sciences, St. John's University, New York, USA

*Corresponding author: Schramm L, Department of Biological Sciences, St. John's University, Queens, New York, 11439, USA, Tel: 7189901315; E-mail: schramml@stjohns.edu

Received date: September 24, 2015; Accepted date: September 26, 2015; Published date: September 29, 2015

Copyright: ${ }^{\odot} 2015 \mathrm{Koo} \mathrm{J}$ et al. This is an open-access article distributed under the terms of the Creative Commons Attribution License, which permits unrestricted use, distribution, and reproduction in any medium, provided the original author and source are credited.

\begin{abstract}
In the United States women have a 1 in 8 lifetime risk for developing breast cancer leading women to turn to natural products for breast cancer prevention. One natural product women have turned to for breast cancer prevention is soy which has been extensively studied for its health benefits. Soy has been classified as a phytoestrogen and as such has been studied as a chemopreventive agent in breast cancer. Results from preclinical and epidemiological studies involving soy have been contradictory. In part, the contradictory results may stem from study design and dietary sources of soy studied. In the US exposure to soy is primarily unfermented soy, but most epidemiological studies reporting breast cancer chemopreventive effects of soy involve fermented soy exposure. Thus, a direct comparison of the effects of unfermented and fermented soy on breast cancer in Western women is warranted.
\end{abstract}

Keywords: Polyphenols; Isoflavones; Unfermented soy; Dietary soy; Breast cancer

\section{Introduction}

Two major bioactive components of soybeans are genistein and daidzein and are structurally classified as isoflavones, a subclass of polyphenols characterized as having two or more ring structures [1]. Soybeans have become the second largest crop in cash sales and the number one export crop in the United States, after corn, and the United States (US) produces $40 \%$ of all soybean crops worldwide [2]. As corn prices and profits continue to decline in 2015 it is anticipated that US farmers will plant a record number of soybeans to offset the decline in corn profits. To understand the potential impact increased soybean crops have on our food supply and human health we must discuss current processing and uses of soybean crops in the US.

The majority of soybean crops are processed into oil and meal. Soybean oil is a major component of shortening, margarine, cooking oil, and salad dressings, accounting for up to 80 percent or more of the edible fats and oils consumed in the United States [3,4]. Soybean meal, a rich source of protein, is processed into soybean flour used in human food and animal feed [5]. The use of soy-based proteins for human consumption continues to grow in the US, as soy protein is currently used in baby formulas, cereals, bread, and various sport and weightloss products. Isoflavones are usually present in the form of glycosides in soybeans and unfermented soy foods, whereas in fermented soy isoflavone aglycones are enriched and have a faster absorption rate [6] which may partially explain differences in the reported health benefits of isoflavones in the literature [7].

With the recent surge of unfermented soy in the US food chain, it is important to note that soy isoflavones are major food-derived phytoestrogens that are structurally similar to estrogen with the capacity to weakly bind to estrogen receptors (ERs) [8]. Approximately 1 in $8(12 \%)$ women in the US will develop invasive breast cancer during their lifetime [9]. As such, the putative estrogenic effect of soy raises the concern that high consumption of soy foods by breast cancer patients and/or women at high risk for breast cancer may increase estrogen-dependent breast tumor growth [10]. The peer reviewed epidemiological literature reports conflicting results regarding soy consumption and breast cancer prevention in preclinical and epidemiological studies. Confounding the ability to determine the effects of dietary soy isoflavones on breast cancer is, in part, because epidemiological studies from Asia compare the effects of fermented soy and in Western countries unfermented soy is the primary exposure. Further, in preclinical studies researchers often use purified components of soy, such as genistein and daidzein, not mixtures of genistein and daidzein in ratios often found in normal dietary sources of soy exposure, further complicating interpretation of soy effects on breast cancer proliferation.

Nagata et al. [11] reviewed the epidemiological studies on soy intake and breast cancer in Japanese women. The authors noted two studies observed that fermented soy intake was associated with a risk reduction of breast cancer in postmenopausal women. Among the case-control studies reviewed, the authors reported a weak inverse association between fermented soy intake and the risk of breast cancer. Authors concluded there is some evidence that supporting a protective effect of isoflavones on breast cancer risk in Japanese women consuming fermented soy. Recently, Chen et al. [12] performed a meta-analysis of 35 epidemiological studies which reported results of association between soy intake and breast cancer risk for pre- and/or post-menopausal women, and further explored the soy and breast cancer association focusing on Study County and design. Authors concluded that soy isoflavone intake may lower the risk of breast cancer for both pre and post-menopausal women in Asian countries [12], but no such conclusions could be make for women in Western countries.

In 2014, Shike et al. examined the effects of soy supplementation on gene expression in breast cancer involving 140 women with early-stage invasive breast adenocarcinoma in a randomized placebo-controlled study [13]. Adherence to soy consumption protocol was determined by HPLC analysis of plasma samples before and after treatment for all participants. The soy treatment group had a seven-fold increase in 
plasma genistein and a four-fold increase in plasma daidzein from daily soy protein powder (51.6 mg/day) supplementation. Study participant demographics and clinicopathological characteristics including age, race, menopausal status, cancer stage, tumor estrogen receptor (ER) status, HER2 status (by IHC and FISH) showed no differences between placebo and soy treatment groups. Further, there were no statistically significant differences in participants' baseline weight, BMI, or alcohol ingestion between groups. The study concluded that short term soy protein supplementation resulted in overexpression of genes, in a subset of women with breast cancer, driving cell cycle and proliferation pathways. This is one of the first studies raising the concern that unfermented soy supplementation may adversely affect some women with breast cancer and warrants further investigation [13]. This is of great importance in light that the quality assurance issues have been identified in protein-containing dietary supplements which up to $40 \%$ of adults use or have used in the US [14]. This study leaves the scientific community to ponder if the study was repeated using fermented soy, would the outcome have been the same?

It is well document that breast cancer metastasizes to bone, brain, liver, and lung [15]. The role of dietary soy in the metastasis of breast cancer is not well studied. Yang et al. [16] examined the effects of genistein, daidzein, (-)-equol or a mixture of soy isoflavones on breast cancer with bone micro-metastasis using murine mammary cancer $4 \mathrm{~T} 1$ cells engineered with a reporter and in a mouse model for breast cancer with bone micro-metastasis and demonstrated that soy isoflavones stimulate breast cancer with bone micro-metastasis in mice. This study highlights the need for further investigation of the effects of unfermented soy supplementation in women.

As dietary exposure to unfermented soy continues to increase in the US it is important to correctly analyze the benefits and risks associated with unfermented soy exposure. Much how the US federal funding agencies have recently required funding applicants to report inclusion of male and female cells and animals in preclinical studies in all funding applications [17], to help clarify sex differences in scientific studies, inclusion of both fermented and unfermented soy in scientific studies examining the risks and benefits of dietary sources of soy exposure in breast cancer is warranted.

\section{References}

1. Beecher GR (2003) Overview of dietary flavonoids: nomenclature, occurrence and intake. J Nutr 133: 3248S-3254S.

2. Bellaloui N, Bruns HA, Abbas HK, Mengistu A, Fisher DK, et al. (2015) Agricultural practices altered soybean seed protein, oil, fatty acids, sugars, and minerals in the Midsouth USA. Front Plant Sci 6: 31.
3. Clemente TE, Cahoon EB (2009) Soybean oil: genetic approaches for modification of functionality and total content. Plant Physiol 151: 1030-1040.

4. Blasbalg TL, Hibbeln JR, Ramsden CE, Majchrzak SF, Rawlings RR (2011) Changes in consumption of omega- 3 and omega- 6 fatty acids in the United States during the 20th century. Am J Clin Nutr 93: 950-962.

5. Gatrell S, Lum K, Kim J, Lei XG (2014) Nonruminant Nutrition Symposium: Potential of defatted microalgae from the biofuel industry as an ingredient to replace corn and soybean meal in swine and poultry diets. J Anim Sci 92: 1306-1314.

6. Izumi T, Piskula MK, Osawa S, Obata A, Tobe K, et al. (2000) Soy isoflavone aglycones are absorbed faster and in higher amounts than their glucosides in humans. J Nutr 130: 1695-1699.

7. He F, J Chen (2013) Consumption of soybean, soy foods, soy isoflavones and breast cancer incidence: Differences between Chinese women and women in Western countries and possible mechanisms Food Science and Human Wellness 2: 141-161.

8. Casanova M, You L, Gaido KW, Archibeque-Engle S, Janszen DB, et al. (1999) Developmental effects of dietary phytoestrogens in SpragueDawley rats and interactions of genistein and daidzein with rat estrogen receptors alpha and beta in vitro. Toxicol Sci 51: 236-244.

9. Siegel RL, Miller KD, Jemal A (2015) Cancer statistics, 2015. CA Cancer J Clin 65: 5-29.

10. Rietjens IM, Sotoca AM, Vervoort J, Louisse J (2013) Mechanisms underlying the dualistic mode of action of major soy isoflavones in relation to cell proliferation and cancer risks. Mol Nutr Food Res 57: 100-113.

11. Nagata C, Mizoue T, Tanaka K, Tsuji I, Tamakoshi A, et al. (2014) Soy intake and breast cancer risk: an evaluation based on a systematic review of epidemiologic evidence among the Japanese population. Jpn J Clin Oncol 44: 282-295.

12. Chen M, Rao Y, Zheng Y, Wei S, Li Y, et al. (2014) Association between soy isoflavone intake and breast cancer risk for pre- and post-menopausal women: a meta-analysis of epidemiological studies. PLoS One 9: e89288.

13. Shike M, Doane AS, Russo L, Cabal R, Reis-Filho JS, et al. (2014) The effects of soy supplementation on gene expression in breast cancer: a randomized placebo-controlled study. J Natl Cancer Inst 106.

14. Maughan RJ (2013) Quality assurance issues in the use of dietary supplements, with special reference to protein supplements. J Nutr 143: 1843S-1847S.

15. Jin X, Mu P (2015) Targeting Breast Cancer Metastasis. Breast Cancer (Auckl) 9: 23-34.

16. Yang X, Belosay A, Hartman JA, Song H, Zhang Y, et al. (2015) Dietary soy isoflavones increase metastasis to lungs in an experimental model of breast cancer with bone micro-tumors. Clin Exp Metastasis 32: 323-333.

17. Clayton JA, Collins FS (2014) Policy: NIH to balance sex in cell and animal studies. Nature 509: 282-283. 